\title{
ASSESSMENT OF SLEEP QUALITY IN PATIENTS WITH TYPE 2 DIABETES MELLITUS: A PROSPECTIVE OBSERVATIONAL STUDY FROM A TERTIARY CARE CENTRE
}

\author{
Syeda Ramsha Batool, Insia Hasan, Jawed Akbar Dars, Rabisa Batool, Syed Masroor Ahmed, Muhammad Iqbal
}

Jinnah Postgraduate Medical Centre, Karachi Pakistan

\section{ABSTRACT}

Objective: To evaluate the quality of sleep-in patients diagnosed with Type 2 Diabetes Mellitus (T2DM).

Study Design: Prospective observational study.

Place and Duration of Duration: Psychiatry Department and Medicine Ward of Jinnah Postgraduate Medical Centre, Karachi Pakistan, from Apr to Nov 2018.

Methodology: All patients with Type 2 Diabetes Mellitus were included in the study. All cases under age 30, type I diabetes, gestational diabetes and patients with severe illness were excluded. The data of sociodemographic lifestyle factors was collected through a pre-designed semi-structured questionnaire and sleep quality of patients was assessed using Pittsburg Sleep Quality Index (PSQI). The results of the data were analyzed by using SPSS version 24.

Results: Out of 260 patients with Type 2 Diabetes Mellitus, $197(76 \%)$ were female. The mean age of the sample was $55.7 \pm 9.89$ years, with only $54(20.8 \%)$ having normal body mass index. More than $50 \%$ of sample was poor sleepers and educational status was found to be strongly associated with quality of sleep ( $p$-value $<0.05$ ).

Conclusion: The present study indicates that patients with Diabetes Mellitus often experienced sleep irregularities hence poor sleep quality. There is a need to increase the awareness regarding sleep quality among patients and health professionals as well while assessing the patients with Diabetes Mellitus.

Keywords: Diabetes Mellitus Type 2, Glycemic control, Insomnia, Sleep quality.

How to Cite This Article: Batool SR, Hasan I, Dars JA, Batool R, Ahmed SM, Iqbal M. Assessment of Sleep Quality in Patients with Type 2 Diabetes Mellitus: A Prospective Observational Study from A Tertiary Care Centre. Pak Armed Forces Med J 2021; 71(6): 1954-1957.

Doi: https://doi.org/10.51253/pafmj.v6i6.4585

This is an Open Access article distributed under the terms of the Creative Commons Attribution License (https://creativecommons.org/licenses/by-nc/4.0/), which permits unrestricted use, distribution, and reproduction in any medium, provided the original work is properly cited.

\section{INTRODUCTION}

Diabetes Mellitus (DM) is one of the most common causes of non-communicable diseases associated with high morbidity and mortality among the patients. It is characterized by hyperglycemia secondary to either defective insulin secretion, resistance or both. ${ }^{1}$ The incidence of diabetes is increasing worldwide as in 2009 there was 285 million adults with Diabetes Mellitus which increased to 382 million by 2013.2 Pakistan has a rapidly increasing incidence of Diabetes Mellitus having an incidence of 7.1 million adults with DM. At present, Pakistan is at 4 th position worldwide comes at $7^{\text {th }}$ position with 7.1 million adults with diabetes and is estimated to reach 13.1 million by climbing to an alarmingly high 4th position worldwide as far as number of diabetic patients are concerned. ${ }^{2}$ In a recently published population-based survey from Pakistan, authored by Aamir et al the prevalence of type 2 Diabetes Mellitus was found to be $16.98 \% .^{3}$

Normoglycemia can minimize the development of complications of Diabetes Mellitus. Poor manage-

Correspondence: Dr Jawed Akbar Dars, Assistant Professor, Jinnah Postgraduate Medical Centre, Karachi Pakistan

Received: 19 Jun 2020; revision received: 10 Aug 2020; accepted: 18 Aug 2020 ment of Diabetes Mellitus can lead to poor prognosis and further complicates the patient's condition. Therefore, it is emphasized that patients with Diabetes Mellitus should not only have an optimum glycemic control but also engage in healthy activities. Evidence has shown that patients with Diabetes Mellitus are prone to poor sleep quality. ${ }^{4}$ Sleep quality is extremely crucial to assess a person's well-being. Every human being requires an adequate amount of sleep to lead a healthy and productive life. National sleep foundation has stressed upon making good sleep a priority as equal as diet and exercise for overall health. ${ }^{5}$ Poor sleep quality has strong association with various diseases and the patients with poor sleep were found to have difficulty with diabetes control., 6 The risk of diabetes increases by $40 \%$ in patients with poor quality sleep. ${ }^{7}$ Despite the evidence, assessment of sleep and its quality, it has never remained a priority of the treating clinicians.

Uncontrolled DM results in microvascular and macrovascular complications. 8,9 These complications not only cause increased morbidity but life-threatening impediments as well. Diabetes control and complication trial (DCCT) found that intensive glycemic control could prevent or slow the progression of diabetic 
complications. ${ }^{10}$ Patients having poor quality of sleep can have chances of impaired glycemia hence, play a significant role in the development of chronic complications.

DM in addition to causing direct sleep disturbances has also been associated with several chronic illnesses which can impair sleep and quality of life. ${ }^{10}$ Hence, this study was aimed to evaluate sleep quality among the patients with Diabetes Mellitus.

\section{METHODOLOGY}

This was a prospective observational study conducted in diabetic clinic of Medical Unit-III of a tertiary care teaching hospital, Jinnah Postgraduate Medical Centre (JPMC), Karachi in collaboration with department of Psychiatry and behavioral science, from April 2018 to November 2018. A non-probability consecutive sampling technique was used to enroll patients in the study after consent approval was obtained.

Inclusion Criteria: All patients with Type-II Diabetes Mellitus (T2DM) were included in the study

Exclusion Criteria: All patients under age 30, Type-I Diabetes, Gestational Diabetes and patients with severe illness were excluded.

The sample size was calculated using computer program "Select Statistics sample size calculator". Taking Diabetes Mellitus type 2 prevalence of $16.98 \%$, confidence level of $95 \%$, a margin of error of $4 \%$ and a population of $>1$ million, a sample size of 260 was obtained. ${ }^{11}$ After procuring the ethics approval from the Institutional Review Board of JPMC with reference \# F.2-81-IRB/2018-GENL/7040/JPMC, data collection was initiated.

The data of sociodemographic lifestyle factors was collected through a pre-designed semi-structured questionnaire and sleep quality of patients was assessed using Pittsburg Sleep Quality Index (PSQI). The questionnaire evaluates seven aspects of sleep quality i.e., subjective sleep quality, sleep latency, sleep duration, sleep efficiency, sleep disturbance, use of sleeping medications and daytime dysfunction. The data were collected by face-to-face interview after taking an informed written consent from patients.

The data were analyzed by using Statistical Package for the social sciences (SPSS) version 24. The continuous data including the age, body mass index, etc. were presented as mean and standard deviation. The categorical and ordinal data was presented as frequency and percentage. The Pearson's chi-square test of independence was implemented to explore the association between the dependent variable and the independent variables. The $p$-value of $\leq 0.05$ was considered as statistically significant.

\section{RESULTS}

The total number of T2DM patients was 260, with female majority of 198 (76\%). Mean age of the patients was $55.7 \pm 9.89$ with $101(38.8 \%)$ patients above 60 years of age. Majority of the patients were illiterate $146(56.2 \%)$ while 38 (14.6\%) were paid workers. About $107(41.2 \%)$ were living as nuclear families while 153 (58.8\%) lived in joint family system. Out of 209 (80.4\%) of the patients were married while 51 (19.6\%) were single/widowed or divorced. The mean BMI of patients was found to be $28.4 \pm 5.20$ and only 54 (20.8\%) participants were normal weighted in response to the question regarding subjective sleep quality, it was fairly good $116(44.6 \%)$, very good $64(24.6 \%)$, fairly bad 46 $(17.7 \%)$ and very bad $34(13.1 \%)$, with $113(43.5 \%)$ sleeping $<5$ hours and $49(18.8 \%)>7$ hours. $88 \%$ did not take any medicines to help them sleep, patients with age above 60 were mostly poor sleepers. Among the patients, females were more prone to have poor sleep quality in comparison to males and same was the case with illiterate people as compared to literates. Patients who were married, unpaid and those who were living in joint family system were having their global PSQI to be greater than 5. Educational status was found to be strongly associated with quality of sleep $p=0.021$ shown in Table. Out of 260 patients, the majority of them $180(69.2 \%)$ were poor sleepers, that is their global PSQI score was more than 5 (Figure).

\section{DISCUSSION}

Diabetes Mellitus is a metabolic disease with a profound impact on all the systems of the body. It has a direct impact on the quality of life of patients hence, sleep routine is also disturbed. ${ }^{11}$ The current study showed that more than half of the study population were poor sleepers (PSQI>5). Over thirty percent of the participants claimed that their sleep quality was fairly bad or very bad and about two-fifth of them slept for $<5$ hours a day. These findings strongly suggest that patients with diabetes experience sleep disturbances.

In accordance with our findings, Keskin et al reported similar results with more than three-fifth of the patients with Diabetes labelled as poor sleepers $(64.30 \%)$ on PSQI. Moreover, the authors further revealed that $54.40 \%$ of the study participants suffered from extreme daytime sleepiness. ${ }^{11}$

Darraj et al, revealed that $55.4 \%$ of the patients with diabetes experienced poor sleep quality. Further- 
Table: Quality of sleep among type 2 diabetics by sociodemographic factors.

\begin{tabular}{|c|c|c|c|}
\hline Characteristics & $\begin{array}{c}\text { PSQI <5 (Good } \\
\text { Sleepers) } \\
\mathbf{n}=80, \mathbf{n}(\%)\end{array}$ & $\begin{array}{c}\text { PSQI >5 (Poor } \\
\text { Sleepers) } \\
n=180, n(\%)\end{array}$ & $\begin{array}{c}p- \\
\text { value }\end{array}$ \\
\hline \multicolumn{4}{|l|}{ Age Group (Years) } \\
\hline $30-40$ & $1(1.25)$ & $4(2.22)$ & \multirow{4}{*}{0.294} \\
\hline $40-49$ & $21(26.25)$ & 34 (18.89) & \\
\hline $50-59$ & $33(41.25)$ & $66(36.67)$ & \\
\hline$>60$ & $25(31.25)$ & $76((42.4)$ & \\
\hline \multicolumn{4}{|l|}{ Gender } \\
\hline Male & $26(32.50)$ & $36(20)$ & \multirow{2}{*}{0.29} \\
\hline Female & $54(67.50)$ & $144(80)$ & \\
\hline \multicolumn{4}{|l|}{ Marital Status } \\
\hline Married & & & \multirow[b]{2}{*}{0.054} \\
\hline $\begin{array}{l}\text { Single/widowed/ } \\
\text { divorced }\end{array}$ & $\begin{array}{l}08(85) \\
12(15)\end{array}$ & $39(21.67)$ & \\
\hline \multicolumn{4}{|l|}{ Education } \\
\hline Uneducated & $38(4750)$ & $108(60)$ & \multirow{3}{*}{0.021} \\
\hline Primary school & $9(11.25)$ & $26(14.44)$ & \\
\hline Secondary school and & $32(40.25)$ & $46(25.56)$ & \\
\hline \multicolumn{4}{|l|}{ Occupation } \\
\hline In paid work & $16(20)$ & $22(12.22)$ & \multirow{2}{*}{0.101} \\
\hline Not working & $64(80)$ & $158(87.78)$ & \\
\hline \multicolumn{4}{|l|}{ Family Structure } \\
\hline Nuclear & $39(48.75)$ & $68(37.78)$ & \multirow[t]{2}{*}{0.097} \\
\hline Joint & $41(51.25)$ & $112(62.22)$ & \\
\hline \multicolumn{4}{|l|}{ Body Mass Index } \\
\hline Underweight $(<18.5)$ & $1(1.25)$ & $4(2.22)$ & \multirow{5}{*}{0.876} \\
\hline Normal weight & & & \\
\hline$(18.5-24.9)$ & $17(21.25)$ & 37 (20.56) & \\
\hline Overweight (25-29.9) & $30(37.50)$ & 74 (41.11) & \\
\hline Obese $(>30)$ & $32(40)$ & $65(36.11)$ & \\
\hline
\end{tabular}

Sleep Quality Among Study Participants (n=260)

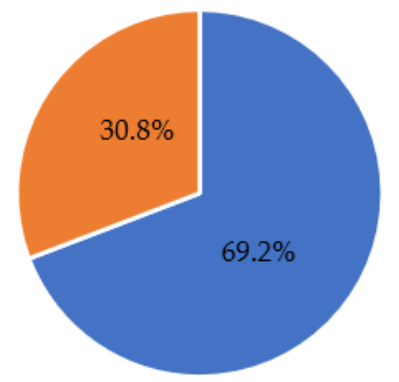

- Poor sleepers

(PSQI $>5$ )

- Good sleepers

$(\mathrm{PSQI}<5)$

Figure: Sleep quality among study participants $(n=260)$.

more, Darraj and his colleagues analyzed the risk factors associated with poor sleep-in patients with Diabetes Mellitus. The authors observed that female gender was the strongest predictor of poor sleep quality among the patients with an odds ratio of 3.65 $(p<0.001) .{ }^{12}$ Similar results were shown by Luyster and Dunbar-Jacob indicating that the majority i.e. $55 \%$ of the patients with diagnosed T2DM suffered from sleep disorder. ${ }^{13}$ However, some studies on patients with DM have shown inconsistent findings, revealing a

much lower frequency of poor sleepers, that is, 38\% and $47.1 \% .14,15$ Moreover, Shamshirgaran et al, revealed no significant association between poor sleep quality and female gender as well as with elderly population. This finding is in line with the current study i.e., despite the higher frequency of poor sleepers in our study, we could not find statistical association between age and gender.

Previously, Lou et al and Nefs et al, have shown a higher prevalence of poor sleepers among females, illiterates, unpaid and older patients. ${ }^{16,17}$ Older and unpaid people might have higher PSQI score because being idle and dependent members of society, they have a poor quality of social life and hence are more prone to stress. However significant association of sleep quality was only found to be with educational status $(p=0.021)$. Prevalence might be high in illiterates due to their lower quality of life and decreased awareness of importance of adequate sleep and its impact on glycemic controls.

In relation to BMI, our results highlighted poor sleepers as mostly over weighted and obese $(41 \%$ and $36 \%$ respectively). This is in congruence with recent studies by Yucel et al and Colbay et al, in which it was shown that higher PSQI scores in patients was associated with abnormal BMI. ${ }^{18,19}$ This can be explained by the release of ghrelin, a hormone that is increasingly secreted in person with short sleep duration. Ghrelin promotes appetite which in turn leads to obesity and poor diabetic control.20,21

According to our study larger proportion of patients were having short sleep hours that is less than 5 hours $(43.5 \%)$. This is in line with a study by Sakamoto et al, demonstrating that the mean sleep hours in diabetes patients was lower than 8 hours a day i.e., $6.23 \pm$ 1.42 hours. ${ }^{22}$ Additionally, Mallon et al, has proven that shorter sleep duration is found be a significant risk factor for DM and therefore majority of patients with diabetes have compromised sleep durations. ${ }^{23}$

The rate of use of sleep medications among T2DM patients was found to be very low (12\%). Another study conducted in China also illustrates lower incidence of use of sleep medications. ${ }^{24}$ This signifies the fact that assessment and treatment of poor sleep is not the part of treatment protocols of Diabetes Mellitus. Another reason may be the fear of addiction of sleep medication in our population which hinders their use even if prescribed by physicians.

In conclusion, the present study indicated that patients with type 2 Diabetes Mellitus suffered from 


\section{Type 2 Diabetes Mellitus}

poor sleep quality. We found that patients who were married or had higher education status had lesser sleep irregularities. Many studies have explored the relationship between marital status and education status. A study by Bukhsh et al, it was reported that sufficient knowledge about Diabetes Mellitus was significantly associated with better self-management of diabetes..$^{25} \mathrm{It}$ is crucial to counsel patients about the disease and how to cope with it according to their education status. Those with no formal education may easily fail to understand the seriousness of their diabetic status, hence, indulge in harmful habits like smoking, consuming non-healthy diet, or non-compliance with the treatment which may worsen their disease and prognosis.

The result of this study provides useful information regarding relation of $\mathrm{T} 2 \mathrm{DM}$ and sleep quality to the physicians to enhance the management of diabetes. This study contributes to the needs of the country, as there are no related studies done in Pakistan assessing sleep quality of diabetes patients.

\section{LIMITATION OF STUDY}

Few limitations of the study include the unequal study population which was majority females. This study included participants from only one diabetes clinic belonging to public sector (JPMC, Medicine ward III), however, this may not represent entire population. We also did not collect information regarding patients' stress level, quality of life, caffeine intake, medications other than that for diabetes. Due to lack of funds, we were not able to prove diabetes control through patients' HbA1c levels.

\section{CONCLUSION}

The present study indicates that patients with Diabetes Mellitus often experienced sleep irregularities hence poor sleep quality. Age, educational, and marital status have association with sleep quality. This, points towards the need to focus on assessment of sleep quality in T2DM patients and increasing awareness among patients concerning the impact of sleep on glycemic control.

\section{Conflict of Interest: None.}

\section{Author's Contribution}

SRB: Study design \& ackquasition, IH: Draft writing, JKD: Supervision \& critical reviw, RB: data acquisition \& interpretation, SMS: Drafting of manuscript, MIA: Supervision \& review.

\section{REFERENCES}

1. American Diabetes Association. Diagnosis and classification of diabetes mellitus. Diabetes Care 2010; 33(Suppl 1): S62-S69.

2. Shaw JE, Sicree RA, Zimmet PZ. Global estimates of the prevalence of diabetes for 2010 and 2030. Diabetes Res Clin Pract 2010; 87(1): 4-14.

3. Aamir AH, Ul-Haq Z, Mahar SA, Qureshi FM, Ahmad I, Jawa A, et al. Diabetes prevalence survey of Pakistan (DPS-PAK): prevalence of type
2 diabetes mellitus and prediabetes using HbA1c: a population-based survey from Pakistan. BMJ Open 2019; 9(2): e025300.

4. Hussain A, Ali I. Diabetes mellitus in Pakistan: A major public health concern. Arch Pharm Pract 2016; 7(1): 30-33.

5. Sleep Foundation. How Much Sleep Do We Really Need? Sleep Foundation 2020 [Internet]. Available at: https://www. sleepfoundation.org/articles/how-much-sleep-do-we-really-need [Accessed on Jun 19, 2020];

6. Taheri S, Lin L, Austin D, Young T, Mignot E. Short sleep duration is associated with reduced leptin, elevated ghrelin, and increased body mass index. PLoS Med 2004; 1(3): e62.

7. Anthaisintawee T, Reutrakul S, Cauter EV, Thakkinstian A. Sleep disturbances compared to traditional risk factors for diabetes development: systemic review and meta-analysis. Sleep Med Rev 2016; 30(1): 11-24.

8. Papatheodorou K, Papanas N, Banach M, Papazoglou D, Edmonds M. Complications of diabetes. J Diabetes Res 2016; 2016(Special Issue): 1-3.

9. Shah A, Kanaya AM. Diabetes and associated complications in the South Asian population. Curr Cardiol Rep 2014; 16(5): 476

10. Nathan DM, Genuth S, Lachin J, Cleary P, Crofford O, Davis M, et al. Diabetes Control and Complications Trial Research Group. The effect of intensive treatment of diabetes on the development and progression of long-term complications in insulin-dependent diabetes mellitus. $\mathrm{N}$ Engl J Med 1993; 329(14): 977-986.

11. Keskin A, Ünalacak M, Bilge U, Yildiz P, Güler S, Selçuk EB, Bilgin M. Effects of sleep disorders on hemoglobin A1c levels in type 2 diabetic patients. Chin Med J 2015; 128(24): 3292.

12. Darraj A, Mahfouz MS, Alsabaani A, Sani M, Alameer A. Assessment of sleep quality and its predictors among patients with diabetes in Jazan, Saudi Arabia. Diabetes Metab Syndr Obes 2018; 11: 523-531.

13. Luyster FS, Dunbar-Jacob J. Sleep quality and quality of life in adults with type 2 diabetes. Diabetes Educ 2011;37(3): 347-355.

14. Shamshirgaran SM, Ataei J, Malek A, Iranparvar-Alamdari M, Aminisani N. Quality of sleep and its determinants among people with type 2 diabetes mellitus in Northwest of Iran. World J Diabetes 2017; 8(7): 358.

15. Zhu BQ, Li XM, Wang D, Yu XF. Sleep quality and its impact on glycaemic control in patients with type 2 Diabetes Mellitus. Int J Nurs Sci 2014; 1(3): 260-265.

16. Lou P, Qin Y, Zhang P, Chen P, Zhang L, Chang G, et al. Association of sleep quality and quality of life in type 2 Diabetes Mellitus: a crosssectional study in China. Diabetes Res Clin Prac 2015; 107(1): 69-76.

17. Nefs G, Donga E, van Someren E, Bot M, Speight J, Pouwer F. Subjective sleep impairment in adults with type 1 or type 2 diabetes: results from diabetes MILES-The Netherlands. Diabetes Res Clin Prac 2015; 109(3): 466-475.

18. Yücel SC, Güler EK, Ak I. Investigation of sleep quality, quality of life, anxiety and depression in patients with Diabetes Mellitus. Int J Diabetes Devel Count 2015; 35(1): 39-46.

19. Colbay G, Cetin M, Colbay M, Berker D, Guler S. Type 2 diabetes affects sleep quality by disrupting the respiratory function: J Diabetes 2015; 7(5): 664-671.

20. Taheri S, Lin L, Austin D, Young T, Mignot E. Short sleep duration is associated with reduced leptin, elevated ghrelin, and increased body mass index. PLoS Med 2004; 1(3): e62.

21. Hibi M, Kubota C, Mizuno T, Aritake S, Mitsui Y, Katashima M, et al. Effect of shortened sleep on energy expenditure, core body temperature, and appetite: a human randomised crossover trial. Sci Rep 2017; 7: 39640.

22. Sakamoto R, Yamakawa T, Takahashi K, Suzuki J, Shinoda MM, Sakamaki $\mathrm{K}$, et al. Association of usual sleep quality and glycemic control in type 2 diabetes in Japanese: A cross sectional study. Sleep and Food Registry in Kanagawa (SOREKA). Plos One 2018; 13(1): e0191771.

23. Mallon L, Broman JE, Hetta J. High incidence of diabetes in men with sleep complaints or short sleep duration: a 12-year follow-up study of a middle-aged population. Diabetes Care 2005; 28(11): 2762-2767.

24. Zhu B, Xie M, Park CG, Kapella MC. Adaptation of the Pittsburgh sleep quality index in Chinese adults with type 2 diabetes. J Chin Med Assoc 2018; 81(3): 242-247.

25. Bukhsh A, Khan TM, Sarfraz Nawaz M, Sajjad Ahmed H, Chan KG, et al. Association of diabetes knowledge with glycemic control and self-care practices among Pakistani people with type 2 diabetes mellitus. Diabetes Metab Syndr Obes 2019; 12: 1409-1417. 